\section{Multidisciplinary \\ SCIENTIFIC JOURNAL OF \\ MARITIME RESEARCH}

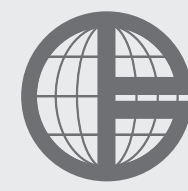

University of Rijeka

Faculty of Maritime

Studies Rijeka
Multidisciplinarni

znanstveni časopis

POMORSTVO

\title{
Analysis of variable Inlet Valve Control in two-stage turbocharged marine four-stroke Diesel engines - Miller cycle
}

\author{
Luka Abramović, Dragan Martinović, Davor Lenac \\ University of Rijeka, Faculty of Maritime Studies, Studentska ulica 2,51000 Rijeka, Croatia, e-mail: dragec@pfri.hr
}

\begin{abstract}
With the ever so imminent threat of climate change caused by man-made pollution, IMO introduces a new piece of legislature: IMO Annex 6 Tier III regarding air pollution. To meet new standards of exhaust air content, engineers are scrambling to find new and efficient ways to keep the shipping industry going. With the dawn of two-stage turbocharging developing high values of inlet air pressure in combination with early IVC using variable valve actuation depending on the engine load, the regulations are met. In this study the effectiveness of the previously mentioned concepts are put to the test against the conventional Diesel cycle used on board most vessels today. A detailed comparison of the two is conducted followed by a thorough analysis and argumentation.
\end{abstract}

\section{ARTICLE INFO}

\section{Review article}

Received 10 May 2017

Accepted 14 June 2017

\section{Key words:}

Variable valve actuation

Two-stage turbocharging

Early IVC

Miller timing

Lower $\mathrm{NO}_{\mathrm{x}}$ content

\begin{abstract}
Abbreviations:
SFOC - Specific Fuel Oil Consumption

IVC - Inlet Valve Closing

TC - Turbocharger/Turbocharging
\end{abstract}

\section{Introduction}

With the introduction of Tier III MARPOL Annex 6 regarding Marine Air Pollution [1] which took effect for all new vessels constructed after $1^{\text {st }}$ January 2016, strict regulations are introduced regarding $\mathrm{NO}_{\mathrm{x}}$ and $\mathrm{SO}_{\mathrm{x}}$ harmful gasses. Among many other options that the engine manufacturers had to choose from, one of them was using Millers early IVC. $\mathrm{NO}_{\mathrm{x}}$ gases form at temperatures around $1200^{\circ} \mathrm{C}$, but successfuly utilizing early IVC opens the possibility of near constant combustion temperatures during all engine operation loads and thus the prevention of unwanted gas contents in the exhaust. After having conducted testing, manufacturers concluded a reduction in SFOC alongside lower concentrations of unwanted gas contents in the exhaust [2]. An impressive 5 - $10 \mathrm{~g} / \mathrm{kWh}$ improvement in SFOC drew the attention of many manufacturers and shipowners considering the recent steady surge of oil prices.
The Miller cycle is an improvement on the conventional Diesel cycle regarding valve actuation timing. Its application is mostly based on early IVC (before BDC). The effect of early IVC is expansion and cooling of air in the cylinder which in turn lowers the cycles starting parameter values (pressure and temperature) causing the aforementioned parameters to decrease in value throughout the cycle.

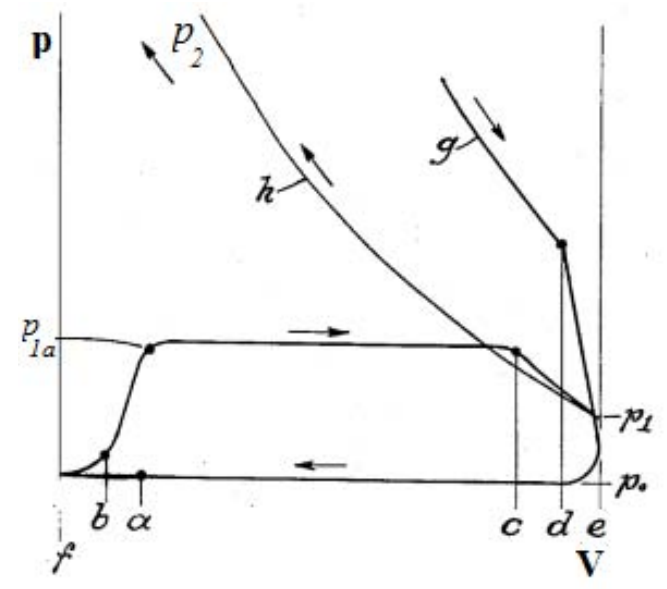

Figure 1 Early IVC in a $\mathrm{p}-\mathrm{V}$ diagram 
With the assumption that the expansion starting at the closing of the inlet valve (c) [5] and ending in BDC is completed adiabatically, follows:

$$
d U=-d L
$$

Since work gained in an adiabatic expansion is solely at the cost of internal energy [3], the movement of the piston towards BDC, after inlet valve closure, produces work and cools the medium.

$$
d(p V)=m R d T
$$

From equations (1) and (2), it follows:

$$
\begin{aligned}
& c_{v} \frac{d(p V)}{R}+p V \frac{d V}{V}=0 \\
& \frac{1}{\kappa-1} \frac{d(p V)}{p V}+\frac{d V}{V}=0 \\
& \int_{c}^{e} \frac{1}{\kappa-1} \frac{d(p V)}{p V}+\int_{V_{c}}^{V_{e}} \frac{d V}{V}=0
\end{aligned}
$$

Completing integration follows:

$p V^{\kappa}=$ konst.

Expanding equation (3) produces a relation between pressure, temperature and volume with which concrete effects of cooling and expansion of the air are noticed.

By computationally rendering the simplified cycle diagram and by calculating the area which the curve encapsulates with the absciss axis, values of work during every thermodynamic state change of the cycle are produced:

$$
d W=\int_{1}^{2} p d V
$$

where it can also be written as:

$$
d W=\text { const. } \int_{1}^{2} \frac{d V}{V^{\kappa}}
$$

With the intention of obtaining a more practical visualisation of data, a marine four-stroke diesel engine MAN L32-40 will be used as an example [6, 7].

Table 1 MAN L32-40 Engine Parameters

\begin{tabular}{|l|c|}
\hline Swept cylinder volume & $32.17 \mathrm{l}$ \\
\hline Stroke & $400 \mathrm{~mm}$ \\
\hline Cylinder bore & $320 \mathrm{~mm}$ \\
\hline Compression ratio & 15.2 \\
\hline Air pressure after turbocharger and cooling & $4.1 \mathrm{bar}$ \\
\hline Inlet air temperature & $61^{\circ} \mathrm{C}$ \\
\hline
\end{tabular}

\section{Conventional Diesel cycle and early IVC cycle}

Calculating characteristic thermodynamic parameters at cycle limits, a clear image of the engines (MAN L32-40) cycle is obtained (Figure 2).

By analysing the diagram in Figure 2, it can be concluded that a higher value of work can be gained (larger area between the curves) through different methods, such as increasing the slope of curve 1-2 (tendency towards $y=V_{2}$ ) which could be accomplished by lowering the value of pressure $p_{1}$. Another method could be increasing the slope of curve 3-4 (tendency towards $y=V_{1}$ ) which would be an option if the duration of fuel injection (2-3) was increased, in other words: value of $V_{3}$ increased.

In order to compare the Miller cycle (early IVC) with the Diesel one, it is necessary to determine the exact moment of the inlet valve closure for every identical starting parameter as for the Diesel cycle and to assume a specific IVC timing to calculate the values in each characteristic point of the cycle.

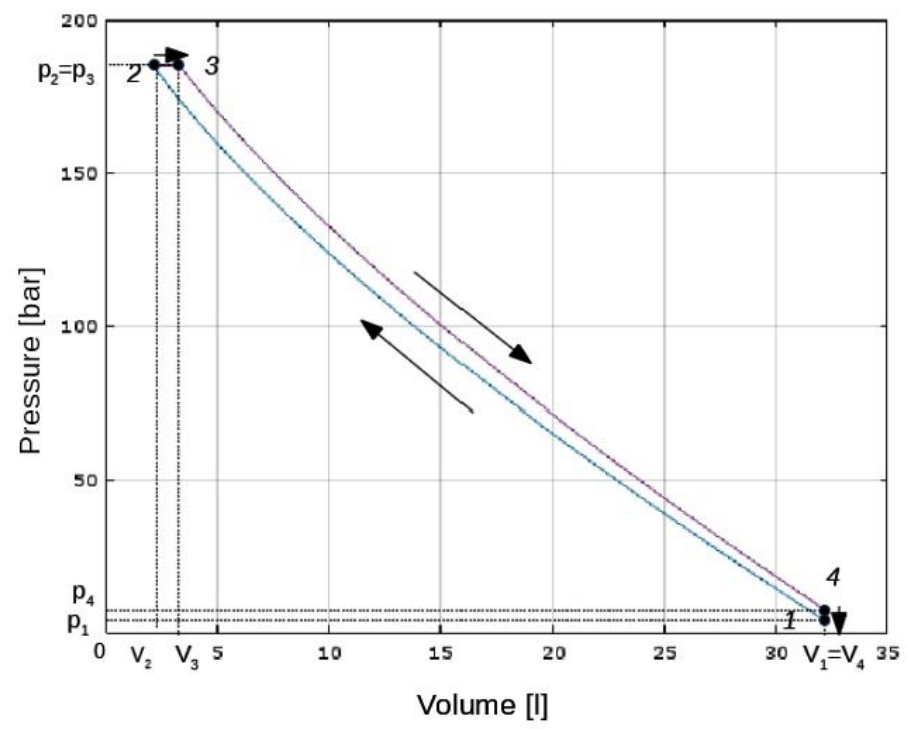

Figure 2 MAN L32 - 40 Diesel Cycle 
Table 2 Pressure and Temperature Drop in Accordance with IVC Timing

\begin{tabular}{|l|c|c|c|c|c|c|c|c|c|}
\hline Angle of IVC & $10^{\circ}$ & $20^{\circ}$ & $30^{\circ}$ & $40^{\circ}$ & $50^{\circ}$ & $60^{\circ}$ & $70^{\circ}$ & $80^{\circ}$ & $90^{\circ}$ \\
\hline Pressure [bar] & 4.06 & 3.96 & 3.79 & 3.56 & 3.27 & 2.93 & 2.56 & 2.17 & 1.77 \\
\hline Temp. [K] & 333.34 & 330.89 & 326.78 & 320.94 & 313.32 & 303.82 & 292.36 & 278.87 & 263.27 \\
\hline
\end{tabular}

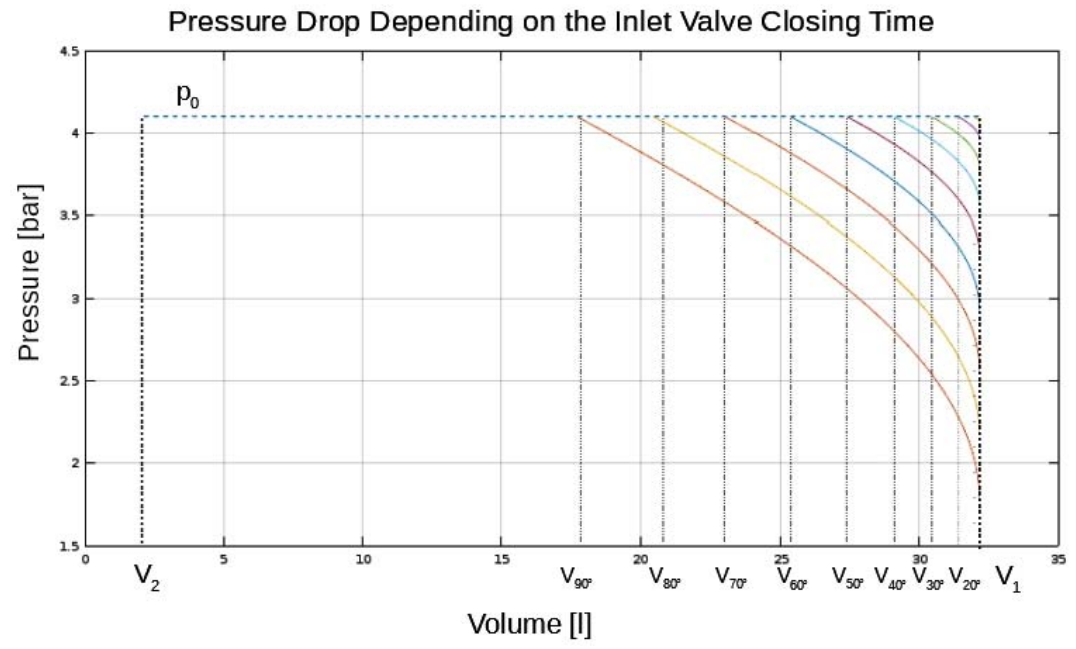

Figure 3 Pressure Drop due to Different IVC Timing

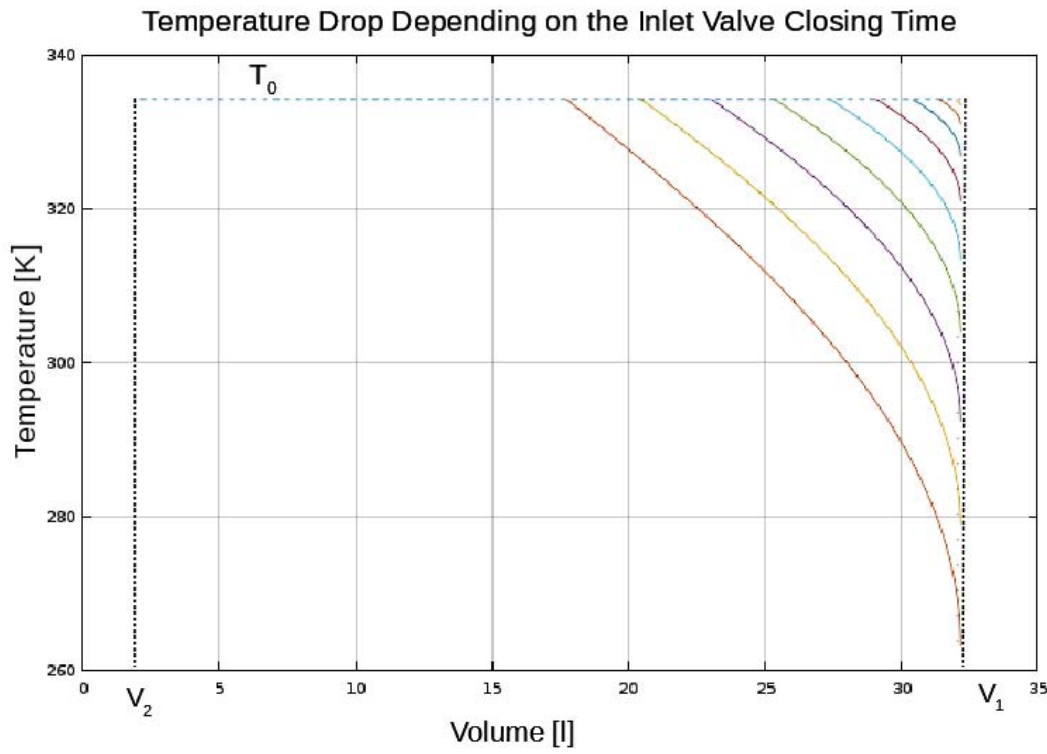

Figure 4 Temperature Drop due to Different IVC Timing

With the increase of the inlet valve closing angle, the exponential increase in pressure and temperature drop is noticed (Table 2). That occurence is due to a non-linear piston travel speed and is clearly visible from Figures 3 and 4.

The analysis of the diagram in Figure 3 leads to a conclusion that at relatively standard values of inlet air pressure $\left(p_{0}=4.1 \mathrm{bar}\right.$ ), extreme Miller timings (early IVC) are in fact detrimental, as a low quantity of air would be ad- mitted to the combustion chamber which would result in a much lower value of produced work. At standard inlet air pressure values, such as is in this example, the optimal Miller timing would be around $10^{\circ}-20^{\circ}$ crank angle before BDC, causing a drop in combustion temperature and pressure without a drastic loss on gained net work.

For an assumed IVC timing of $20^{\circ} \mathrm{crank}$ angle before the BDC temperature and pressure drop, a diagram (Figure 5) is drawn: 


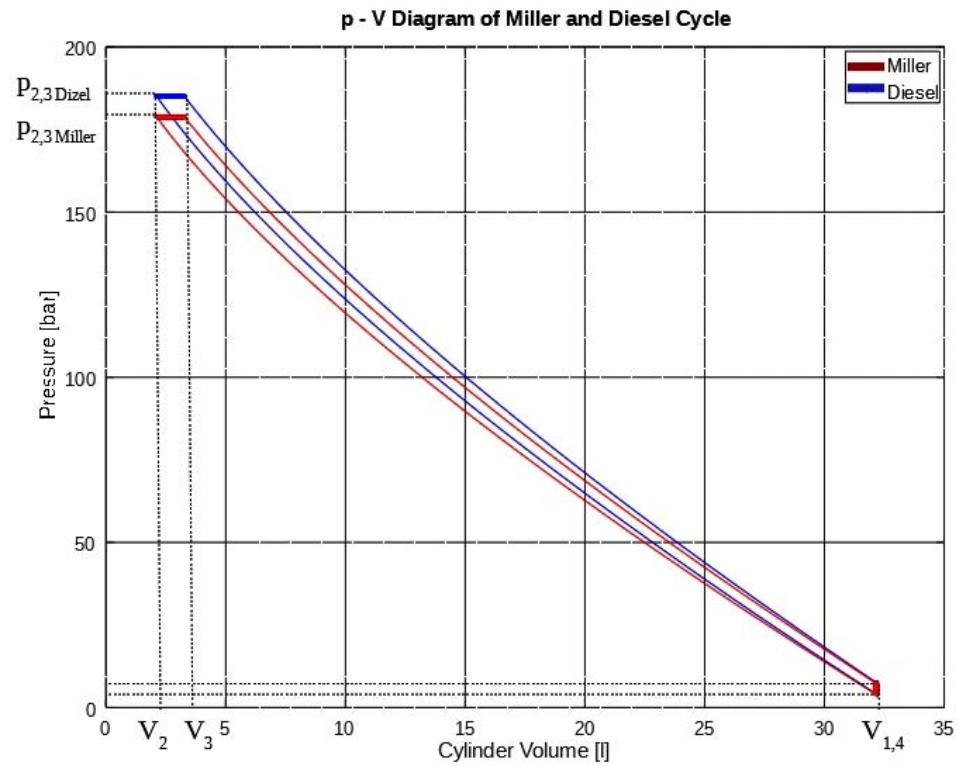

Figure 5 Comparison of the Diesel and Early IVC (Miller) Cycle

By graphically analyzing the $\mathrm{p}-\mathrm{V}$ diagram (Figure 5), it is concluded that the net work gained in the cycle utilizing early IVC is lower than that of a conventional Diesel cycle due to a smaller area between the curves. By using the equation to calculate the area beneath the curves (Eq. 4), as used in the Diesel cycle calculation, it is possible to calculate the net gained work of the early IVC cycle (Table 3 ).

Table 3 Work Gained or Spent in Various Stages of the Cycles

\begin{tabular}{|c|c|c|c|}
\hline & Diesel & Miller & $\boldsymbol{\Delta}$ \\
\hline $\mathrm{W}_{1,2}[\mathrm{~J} / \mathrm{kg}]$ & -254580 & -246000 & -8580 \\
\hline $\mathrm{W}_{2,3}[\mathrm{~J} / \mathrm{kg}]$ & 21895 & 21157 & 738 \\
\hline $\mathrm{W}_{3,4}[\mathrm{~J} / \mathrm{kg}]$ & 253600 & 245060 & 8540 \\
\hline $\mathrm{W}_{\Delta}[\mathrm{J} / \mathrm{kg}]$ & 20913 & 20219 & 694.39 \\
\hline
\end{tabular}

Comparing the individual values of the work in each cycle respectively (Table 3), it is visible that in the Diesel cycle more work is spent on the compression of air (1-2), although in the cycle utilizing Miller timing (early IVC) more work is gained from the expansion of gases (2-3 and $3-4)$. The difference in the gained net work of $694.39 \mathrm{~J} / \mathrm{kg}$ is equivalent to a drop in value of $3.4 \%$.

However, more emphasis should be placed on the combustion temperature drop $\left(\mathrm{T}_{2}\right)$ which, in this case, is $0.9 \%$. Therefore, from a $\mathrm{NO}_{\mathrm{x}}$ formation prevention standpoint, at inlet air pressures of around 4 bar, the application of earlier IVC is unprofitable. Another approach would require a higher quantity of fuel admitted to the cylinder which would in turn raise the value of the combustion pressure. Therefore, it is vital to notice the drop in the combustion pressure $\left(\mathrm{p}_{2}\right)$ value which is also $3.4 \%$. The drop in the pressure value is proportional to work, the work being a function of pressure.
Table 4 Parameter Values at Characteristic Points in the Cycles ( $p_{0}=4.1$ bar $)$

\begin{tabular}{|c|c|c|c|}
\hline \multicolumn{4}{|c|}{ DIESEL } \\
\hline & p [bar] & $\mathbf{T}[\mathrm{K}]$ & V [1] \\
\hline 1 & 4.1 & 334.15 & 32.17 \\
\hline 2 & 185.08 & 992.38 & 2.11 \\
\hline 3 & 185.08 & 1537.25 & 3.27 \\
\hline 4 & 7.56 & 616.64 & 32.17 \\
\hline \multicolumn{4}{|c|}{ MILLER } \\
\hline & p [bar] & $\mathbf{T}[\mathrm{K}]$ & V [1] \\
\hline 1 & 3.96 & 330.89 & 32.17 \\
\hline 2 & 178.84 & 982.71 & 2.11 \\
\hline 3 & 178.84 & 1522.25 & 3.27 \\
\hline 4 & 7.31 & 610.63 & 32.17 \\
\hline
\end{tabular}

After having drawn conclusions on the lowered net work gained and a small combustion temperature drop, a logical step in improving the system would be the increase of inlet air pressure. With the increase of inlet air pressure to around $7-10$ bar [4], the lowered value of the gained net work (in itself power) is compensated, and the combustion temperature is also effectively lowered in the cylinder by means of the extreme Miller timing, leading to great improvements in exhaust air contents regarding new air pollution regulations [1].

\section{Early IVC with two-stage turbocharging}

With the rapid advancement in turbocharger design and manufacturing technology, many manufacturers such as MAN, Yanmar and ABB have started experimenting with two- stage turbocharging. 
For the purpose of proving the previously mentioned Miller timing improvement regarding the increase of inlet air pressure, a value of $p_{0}=8 \mathrm{bar}$ is assumed. Furthermore, a value of $82^{\circ}$ crank angle of early IVC is proposed. Utilizing the same method of calculations as in the previous table (Table 4), it follows:

Table 5 Parameter Values at Characteristic Points in the Cycles $\left(p_{0}=8\right.$ bar $)$

\begin{tabular}{|c|c|c|c|}
\hline & $\mathbf{p}[\mathbf{b a r}]$ & $\mathbf{T}[\mathbf{K}]$ & $\mathbf{V}[\mathbf{l}]$ \\
\hline 0 & 8 & 334.15 & 19.93 \\
\hline 1 & 4.09 & 275.93 & 32.17 \\
\hline 2 & 184.77 & 819.46 & 2.11 \\
\hline 3 & 184.77 & 1269.39 & 3.27 \\
\hline 4 & 7.55 & 509.2 & 32.17 \\
\hline
\end{tabular}

The value of $82^{\circ}$ early IVC is proposed with the intention of producing results similar to those in the Diesel cycle $\left(p_{1}\right.$ i $\left.p_{2}\right)$. Point 0 and the value at that point represents the moment of inlet valve closure. The assumption of the same inlet air temperature values of $334.15 \mathrm{~K}$ was also made in both cases. Air coolers (heat exchangers), following the air flow after the turbocharger (in this case after each of the two stages), are assumed to be correctly read- justed in accordance with retaining the same air inlet temperature value $\left(T_{0}=334.15 \mathrm{~K}\right)$.

The blue curve (upper) (Figure 6) represents the inlet air pressure drop $\left(p_{1}\right)$, and the red curve (lower) represents the combustion pressure drop $\left(p_{2}\right)$. The blue line (dashed and dotted) labeled with 'Diesel cycle inlet air pressure' is of value $p_{0 \text { DIESEL }}=4.1$ bar and serves as a reference for the comparison of inlet air pressure in the current example where the inlet air pressure is 8 bar. The blue dot on that line marks an intersection of the two-stage TC early IVC inlet air pressure curve and the air inlet pressure of the conventional Diesel cycle. That means that at that angle of crankshafts rotation when the inlet valve closes, the drop in inlet air pressure will be such as to cause $p_{1 \text { two-stage TC }}$ to be equal to $p_{0 \text { DIESEL }}$. The same applies to the red curve and line 'Diesel cycle combustion pressure' (dashed and dotted). That exact value of the early inlet valve closure corresponds to the forementioned assumption of $82^{\circ} \mathrm{crank}$ angle before BDC, and for that reason the assumption was made in the analysis.

Due to approximately equal values of pressures during the entire process, it is unnecessary to produce a $\mathrm{p}-\mathrm{V}$ diagram for comparison, as this would not yield to be able to spot the difference between them. The proof is presented in the next table (Table 6) which shows differences in parameter values between the Diesel cycle and the early IVC one ( $p_{0}=8$ bar $)$.

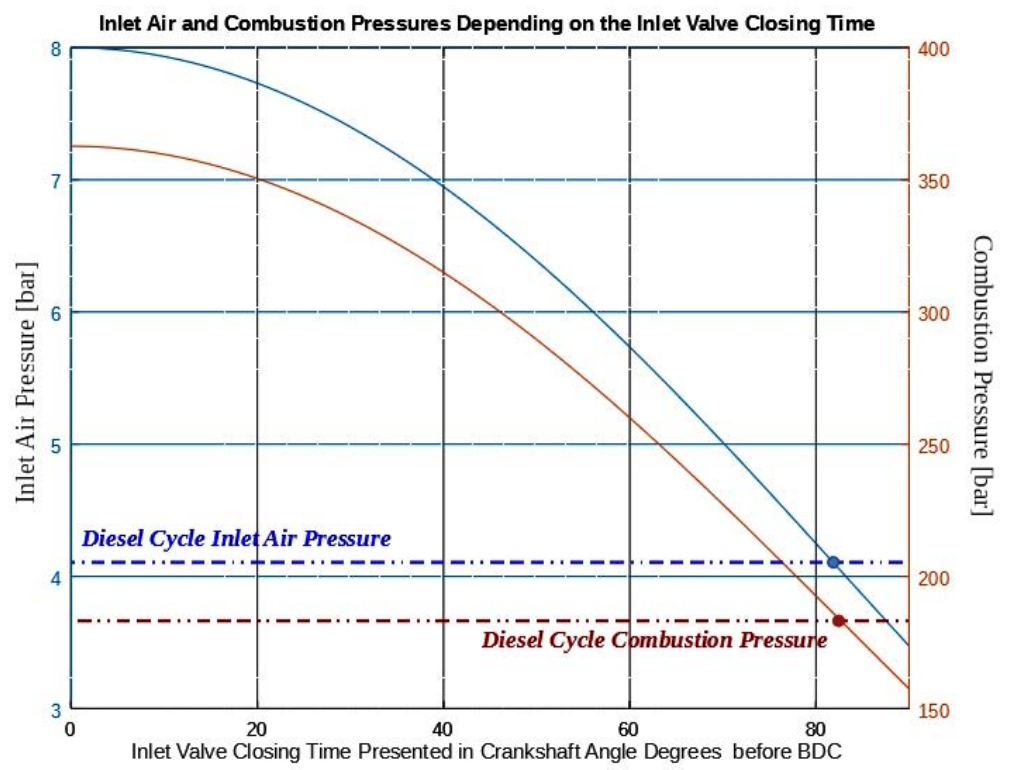

Figure 6 Inlet Air and Combustion Pressure Values in Proportion with Valve Closure Timing

Table 6 Deviations in Parameter Values between Diesel ( $p_{0}=4.1$ bar $)$ and Early IVC $\left(p_{0}=8\right.$ bar) cycle

\begin{tabular}{|c|c|c|c|c|c|c|c|c|}
\hline & \multicolumn{2}{|c|}{1} & \multicolumn{2}{|c|}{2} & \multicolumn{2}{|c|}{3} & \multicolumn{2}{|c|}{4} \\
\hline & p [bar] & $\mathrm{T}[\mathrm{K}]$ & p [bar] & $\mathbf{T}[\mathbf{K}]$ & p [bar] & $\mathbf{T}[\mathbf{K}]$ & p [bar] & $\mathrm{T}[\mathrm{K}]$ \\
\hline Diesel & 4.1 & 334.15 & 185.08 & 992.38 & 185.08 & 1537.25 & 7.56 & 616.64 \\
\hline Difference & $\underline{0.01}$ & $\underline{58.22}$ & $\underline{0.31}$ & $\underline{172.92}$ & $\underline{0.31}$ & $\underline{267.86}$ & $\underline{0.01}$ & $\underline{107.44}$ \\
\hline
\end{tabular}




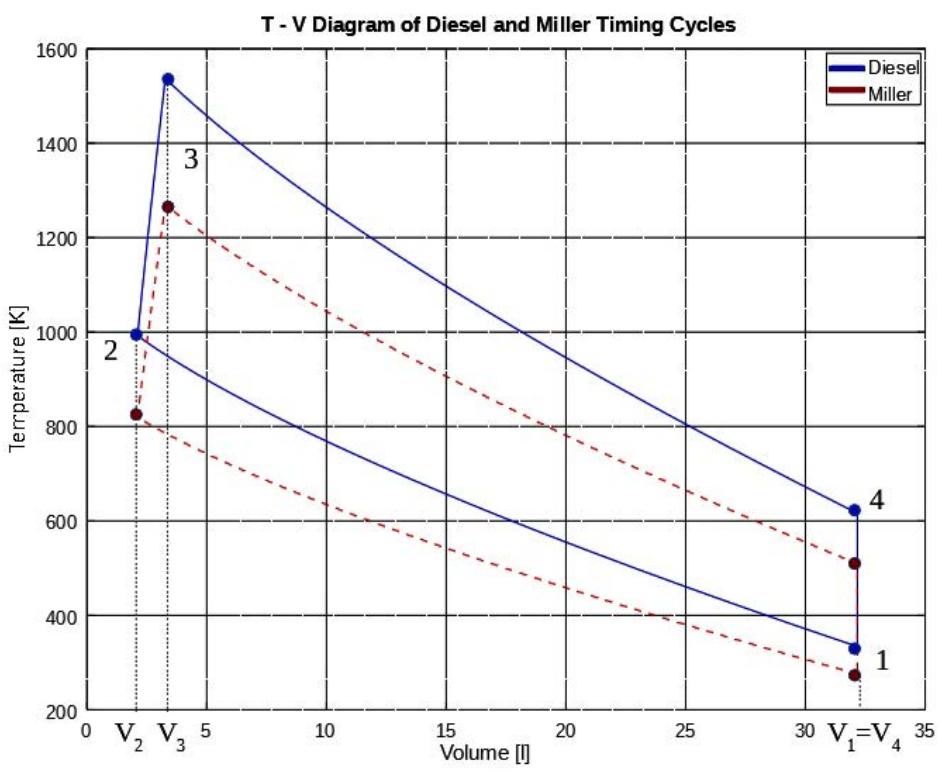

Figure $7 \mathrm{~T}-\mathrm{V}$ Diagram of Diesel and Early IVC $\left(p_{0}=8\right.$ bar $)$ Cycles

The loss in pressure between the entirety of the two cycles is negligible, which points to the fact that the loss in work gained is also very minor. In accordance with previous methods of calculating net work gained, the early IVC ( $p_{0}=8$ bar) cycle net work gained is:

$W_{\triangle e a r l y I V C 8 \text { bar }}=20,893 \mathrm{~J} / \mathrm{kg}$

The difference in net work gained between the two cycles is as follows:

$\Delta W=W_{\triangle D I E S E L}-W_{\triangle e a r l y I V C 8 \mathrm{bar}}=20,913-20,893=19.88 \mathrm{~J} / \mathrm{kg}$

Such a miniscule difference in values of net worked gained between the two cycles is practically inconsequential, and, therefore, the advantage of the currently discussed early IVC cycle is clearly shown.

Unlike pressure values in this example, which are roughly equal throughout entire both cycles, temperatures deviate significantly. That deviation is instantly spotted on the $\mathrm{T}-\mathrm{V}$ diagram (Figure 7), which showcases the rise and fall of temperature values throughout the whole cycle in accordance with the piston travelling in the cylinder.

Lowering of the value of the cycle starting temperature (Figure 7) $T_{1}$ causes a significant drop in temperature values along the entire cycle. It is visible on the diagram that the temperature in point ' 1 ' is lowered by a relatively small amount (compared to the temperature value drop in other points), but still drastically affects the rest of the cycle.

The combustion temperature drop value of around $270^{\circ} \mathrm{C}$ enables prevention of $\mathrm{NO}_{\mathrm{x}}$ molecule formation and other harmful substances to the environment contained in the exhaust gases of conventional engines. In order to satisfy the IMO air pollution regulations regarding exhaust gases, the proposed early IVC cycle in combination with two-stage turbocharging presents a significant improvement compared to the current engine cycles.
If IMO regulations were to be disregarded, a different approach mentioned before could be adopted, such as a longer fuel injection interval could be. However, if the fuel injection interval is to be increased to the point of the combustion temperature of the early IVC cycle $\left(p_{\text {2early IVC }}\right)$ being equal to the combustion temperature of the Diesel cycle $\left(p_{2 \text { DIESEL }}\right)$, then there would be an increase in the engines thermal efficiency as well as net gained work and in turn power.

\section{Conclusion}

With the rapid advancement in turbocharger technology and introduction of a new two-stage turbocharging concept which enables turbochargers to develop high air inlet pressures, it is necessary to reduce the starting air pressure and temperature in order to guarantee safe combustion, as high combustion pressures which could destroy the engine. Instead of reinforcing the engine with stronger materials to withstand immense pressures and temperatures, the ability to lower the aforementioned initial values with early or late IVC (Miller timing) seems to be a logical choice. Applying variable inlet valve closing and opening in dependance to engine load enables optimal combustion in all operating conditions along with lowered combustion temperature values compared to conventional cycles. With the application of such a variable valve actuating system, the intensity of negative effects of an early IVC cycle, such as excessive smoking at low loads [4] alongside with high SFOC and low power output, are greatly reduced.

Although two-stage turbochargers are expensive to implement, the advance of technology and ease of production of such turbochargers will greatly improve with the progression of time, and the implementation cost on to existing engines will surely decline. The same applies to variable valve actuation. It is a necessary step forward in the direction the 
industry is heading: low (or preferably no) emissions for the sake of the environment, and the ability to produce power in a cheap, clean and effective manner. In combination with other emission improving devices (EGR, SCR, Dual-fuel), the application of two-stage turbochargers in tandem with early IVC (variable valve technology) is an imperative in combating climate change and man-made pollution.

\section{References}

[1] IMO NOX Tier III requirements to take effect on January $1^{\text {st }}$ 2016, 17.12.2015, https://www.dnvgl.com/news/ imo-nox-tier-iii-requirements-to-take-effect-on-january1st-2016-51970 (14.04.2017)

[2] DieselNet - What's New? Conference report 2016 CIMAC Congress, 28.06.2016, http://www.cimac.com/cms/upload/ special_printings/diesel_net_2016_06_28_news_Conference_report_2016_CIMAC_Congress.pdf (05.04.2017)
[3] Dr. ing. Bošnjaković, F.: "Nauka o Toplini - Prvi dio", 5. ed., Tehnička knjiga, Zagreb, 1978.

[4] Christer Wik, Björn Hallbäck: "Reducing Emissions Using 2-stage Turbo Chargers”, WÄRTSILÄ TECHNICAL JOURNAL, 01.2008.

[5] Miller, R.: "High Pressure Supercharging System", United States Patent Office, 02.03.1954, Milwaukee,Wisconsin.

[6] "L32/40 Project Guide - Marine", MAN Diesel \& Turbo, 11.11.2013, Augsburg, Germany.

[7] "32/40 Project Guide - Stationary”, MAN Diesel \& Turbo, 06.05.2013, Augsburg, Germany.

[8] Martinović, D.: Analiza brodskih pomoćnih sustava s gledišta sigurnosti poriva broda, doktorska disertacija, Sveučilište u Rijeci, Pomorski fakultet u Rijeci, Rijeka, 2009.

[9] Bernečić, D., Martinović, D., Tudor, M.: The effect of Multiple Fuel Injection on Combustion Profiles in Slow-Speed TwoStroke Marine Diesel Engines, Transactions of FAMENA, Vol. 36, No. 4, pp. 49-62, Fakultet strojarstva i brodogradnje, Sveučilište u Zagrebu, Zagreb, 2012. 